\title{
Potential of Texture Analysis for Charcoal Classification
}

\author{
Bruno Geike de Andrade ${ }^{1}$ (D), Benedito Rocha Vital² (D), \\ Angélica de Cássia Oliveira Carneiro ${ }^{2}$ (D), Vanessa Maria Basso ${ }^{3}$ (D), \\ Francisco de Assis de Carvalho Pinto ${ }^{4}$
}

${ }^{1}$ Instituto de Florestas, Universidade Federal Rural do Rio de Janeiro - UFRRJ, Seropédica/RJ, Brasil ${ }^{2}$ Departamento de Engenharia Florestal, Universidade Federal de Viçosa - UFV, Viçosa/MG, Brasil ${ }^{3}$ Departamento de Silvicultura, Universidade Federal Rural do Rio de Janeiro - UFRRJ, Seropédica/RJ, Brasil

${ }^{4}$ Departamento de Engenharia Agrícola, Universidade Federal de Viçosa - UFV, Viçosa/MG, Brasil

\begin{abstract}
Charcoal produced from reforested wood can be distinguished from the charcoal derived from the wood of native species. This identification is very important for the trade, control and monitoring of charcoal production in Brazil. This study investigated the potential of texture analysis for classifying the charcoal based on origin (eucalyptus or native) and species. A total of 17 wood species were studied, five of which belonged to genus Eucalyptus and 12 were native to the Zona da Mata Mineira. Texture features based on the gray level co-occurrence matrix were extracted from digital images. The linear discriminant analysis was used to classify the images with these features. Employing 10 features, $96.2 \%$ accuracy was achieved for the classification by origin and $90.4 \%$ for the categorization by species. Texture analysis was shown to be a favorable and effective method that could facilitate the establishment of semiautomated techniques to classify the charcoal based on origin or species.
\end{abstract}

Keywords: discriminant analysis, gray level co-occurrence matrix, image analysis. 


\section{INTRODUCTION}

Wood species are distinctively identified by the physical aspects of the tree, such as the trunk shape, leaves and flowers (Ibrahim et al., 2017). When wood alone is available, the analysis assumes greater complexity, requiring time and knowledgeable specialists and needs to be performed based on the macro- and microscopic characteristics (Oliveira et al., 2015). Hence, species identification from wood alone is heavily dependent upon the specialists. However, there is some limitation as these specialists are not always available and their efficiency is highly dependent on their experience and ability to pay attention to detail (Wang et al., 2013). Thus, with the escalating demand for timber and rigorous international trade regulations, more efficient tools for identification need to be developed and used so that fraud can be arrested and illegalities identified (Zamri et al., 2016).

In light of these facts, researchers from different fields recently explored a wide spectrum of studies and offered a variety of alternatives to tackle the issue of species recognition from wood (Martins et al., 2015). According to Paula et al. (2014) these alternatives can be distinguished into spectroscopy-dependent techniques and image analysis-dependent techniques. Among the first group, the works of Piuri \& Scotti (2010), Oliveira et al. (2015), and Nisgoski et al. (2017a, b) rank high. Among the image-analysis studies, those of Khalid et al. (2008), Wang et al. (2013), Yusof et al. (2013), Paula et al. (2014), Martins et al. (2015), Zamri et al. (2016), and Ibrahim et al. (2017) are eminent. Both techniques revealed acceptable results. In general, the analysis of images appears to offer more promise, with satisfactory results when large databases are used, as evident from the research by Yusof et al. (2013) who, in their classification of 52 woody species, achieved $98.67 \%$ accuracy.

Nevertheless, in Brazil, besides the need for identifying species from wood, species recognition from carbonized wood has also become a necessity. Brazil, according to the FAO (2017), is the largest global charcoal producer. A large part of this output is used by the domestic market, particularly for pig iron and steel (AMS, 2013). However, because the country is unable to meet its total demand by producing charcoal from reforestation wood, the illegal use of the native forests has escalated to become an economically attractive activity. The IBÁ (2017) declared that $16 \%$ of all the charcoal produced in Brazil in 2016 originated from native forest wood.

Species recognition from charcoal is accomplished by studying the anatomy of the wood preserved in the charcoal (Scheel-Ybert \& Gonçalves, 2017). Such analysis involves greater complexity than the recognition of species from wood. Therefore there is a need that the specialist possesses vast experience and high ability to pay attention to detail (Nisgoski et al., 2015). Although charcoal identification is a very complicated process, investigations of control and inspection can be carried out in a more simplified way by distinguishing between the charcoals derived from the native species and reforestation species (specifically those belonging to genus Eucalyptus sp.).

In an attempt to tackle this issue, much research has been conducted aiming at characterizing the charcoals from different species and dispensing a subsidy for recognition from the anatomy (Muñiz et al., 2012a, b; Nisgoski et al., 2012; Gonçalves et al., 2012, 2014, 2016; Gonçalves \& Scheel-Ybert, 2016; Muñiz et al., 2016; and Scheel-Ybert \& Gonçalves, 2017). However, only a few research works have sought innovations that will facilitate recognition of species through charcoal compared with the number of innovations being proposed for the recognition through wood.

Some earlier studies have explored the use of spectroscopy techniques in this cause (Muñiz et al., 2013; Nisgoski et al., 2015; Ramalho et al., 2017). All these endeavors were promising, although Ramalho et al. (2017) reported efficiency loss in the spectroscopic technique when the charcoal was produced at high carbonization temperatures. However, until the present, there are no studies available that have explored image analyses for species recognition from charcoal.

From the findings discovered earlier in the literature, texture analysis is expected to facilitate the classification of the charcoal images based on origin and species, with a greater degree of accuracy than by random classification. This work aimed at verifying the potential of using texture analysis in macroscopic images to be able to distinguish between the wood-produced charcoals of the eucalyptus species and those produced from the native species (classification by origin), as well as to recognize the species. 


\section{MATERIALS AND METHODS}

\subsection{Preparation of samples and images acquisition}

The procedures were performed at the Wood Panels and Energy Laboratory (LAPEM) of the Federal University of Viçosa. The material under study was supplied by LAPEM charcoal collection. It included carbonized wood samples from 17 species and hybrids of the genus Eucalyptus and native forest species characteristic of the Zona da Mata Mineira and the Atlantic Forest (Table 1). The species were selected depending on their occurrence in the region, the tendency to utilize wood for charcoal production, as well as the availability of material to conduct the research. The samples of each species/hybrid were collected from a single tree, but without differentiating among the samples in terms of the positions on the trunk height.

Following the procedure adopted by Muñiz et al. (2012a, b; 2016), a muffle furnace was used to perform the carbonization. The carbonization step kept the initial temperature at $150{ }^{\circ} \mathrm{C}$ with an increment of $50^{\circ} \mathrm{C} / \mathrm{h}$ until a final temperature of $450^{\circ} \mathrm{C}$ was achieved, totalizing $7 \mathrm{~h}$ of carbonization.

The charcoal pieces were subjected to transverse sectioning using a metal saw blade and then sanded, in sequence, with sandpapers of 600 and 1500 grain size. This was done to minimize the marks and other patterns that did not match the anatomy of the charcoal, like the marks from the metal saw.

The images were acquired using a Pixelink camera, model PL-A662 coupled to a ZEISS Stemi 2000-C stereoscopic magnifying glass with a magnification of 25 times. The images were produced with dimensions of $1280(\mathrm{H}) \times 1024(\mathrm{~V})$ pixels, spatial resolution of $3.8 \mu \mathrm{m} /$ pixel and 8-bit pixel depth.

Two 20-Watt incandescent light sources, enclosed by parchment paper to reduce the direct light, were placed roughly $4 \mathrm{~cm}$ from the charcoal sample. The light projections were directed in opposite directions, at a $45^{\circ}$ angle to the surface. Photographs of each charcoal sample were taken in cross-section, at the heartwood and sapwood regions, in such a manner that the rays revealed verticality in the center of the image and origin in the lower portion of the image. Those areas of the charcoal possessing de-characterization of the anatomical structure from the carbonization were disregarded.

A total of 50 images were taken for each species/hybrid, and 100 images (50 of each clone) were produced for Eucalyptus urophylla. Finally, a total of 900 images were collected and utilized without preprocessing.

Table 1. Species and hybrids studied (common and scientific names).

\begin{tabular}{|c|c|}
\hline Common name & Scientific name \\
\hline Angico vermelho & Anadenanthera peregrina Speg. \\
\hline Brauninha & Dictyoloma vandellianum A. Juss. \\
\hline Camaldulensis & Eucalyptus camaldulensis Dehnh. \\
\hline Cedrinho & Trattinnickia ferruginea Kuhlm. \\
\hline Grandis $\times$ Camaldulensis & Eucalyptus grandis $\times$ Eucalyptus camaldulensis \\
\hline Mama de porca & Zanthoxylum rhoifolium Lam. \\
\hline Pimenteira & Xylopia sericea A. St.-Hil. \\
\hline Ruão & Vismia martiana H. G. Reich \\
\hline Urocam & Eucalyptus urophyla $\times$ Eucalyptus camaldulensis \\
\hline Urograndis & Eucalyptus. urophyla $\times$ Eucalyptus grandis \\
\hline Urophylla (clone A) & Eucalyptus urophylla S. T. Blake \\
\hline Urophylla (clone B) & Eucalyptus urophylla S. T. Blake \\
\hline Casca doce & Alchornea glandulosa Poepp. \& Endl. \\
\hline Goiabeira & Psidium guajava $L$. \\
\hline Pau fumo & Piptocarpha macropoda Baker \\
\hline Quaresminha & Miconia candolleana Triana \\
\hline Cedro & Cedrella fissilis Vellozo \\
\hline Casuarina & Casuarina equisetifolia $\mathrm{L}$. \\
\hline
\end{tabular}


The qualitative anatomical characteristics were briefly evaluated and compared to offer a subsidy for the discussion of the findings drawn from the classifications. Descriptions were made based on the list of macroscopic anatomical characteristics proposed by IAWA Committee (1989).

\subsection{Extraction of texture features}

After this stage, the whole methodology was done using the MATLAB ${ }^{\circledR}$ software environment (MathWorks, 2017). For each image, 20 gray level co-occurrence matrices (GLCM) were created by combining 5 distance values $\mathrm{d}(1,2,3,4$ and 5 pixels) and 4 angles $\theta\left(0^{\circ}, 45^{\circ}, 90^{\circ}\right.$ and $\left.135^{\circ}\right)$, adopting the methodology of Haralick et al. (1973).

Using the method proposed by Haralick et al. (1973), six basic texture features were calculated for each GLCM, as listed: Second Moment, Variance, Entropy, Contrast, Correlation and Homogeneity. Thus, a total of 120 texture features were collected in the database, which included 900 observations.

\subsection{Selecting the texture characteristics}

The features were selected employing the "sequentialfs" function and the complete database was used as the input data. The "sequentialfs" function performs a sequential selection of features, commencing with an empty feature set and sequentially including new features. According to MathWorks (2017), this function accomplishes 10 cross-validations for each feature, using different automatically selected training and validation subsets, and in each sequence a "criterion" function enables the classification error to be calculated. Thus, features are added to the subset in order to reduce the classification error.

The features were chosen to select those subsets that would most clearly classify the samples in terms of origin (eucalyptus or native) and in terms of species. Subsets with 15,10 and 5 features were selected. As a criterion function, we used the "classify" function to calculate the classification error. According to MathWorks (2017), the "classify" function utilizes the linear discriminant analysis, otherwise termed "Fisher Discriminant", after its inventor R. A. Fisher (Fisher, 1936).

\subsection{Training, validation and comparison of classifiers}

The subsets of the features identified in the earlier step were assessed using the cross-validation model called leave one out. This meant that while all the observations are evaluated, one by one, when one observation is selected, the classification model is trained to utilize all the data barring the observation data being evaluated. The classification was done employing the linear discriminant analysis using the classify function. Two classification types were evaluated, by origin (Eucalyptus or native) and by species, and three databases were used, referring to the subsets of the 15,10 and 5 features.

For the classification by origin, an adapted form of cross-validation leave one out was also calculated. In this adaptation, when one observation was chosen for validation, all the observations of that species were eliminated as well from the training set. In practice, this procedure means that at every leave one out stage, the sample tested by the model originated from a species that the model had not been trained to classify.

From the findings of the cross-validations, error matrices were set up, according to Congalton (1991). Using these matrices, the Kappa coefficients were estimated and their variances were evaluated adopting the method cited by Hudson \& Ramm (1987).

Finally, adopting the $\mathrm{Z}$ Test at the 5\% confidence level, the performances of the classifications were verified to observe whether it was better than a random distinction $(K=0)$. Subsequently, at the $5 \%$ confidence level, the Kappa coefficients of the classifications were compared, two to two, via the same test.

\section{RESULTS AND DISCUSSION}

The preparation of the sample surfaces ensured satisfactory visualization of the macroscopic anatomical structure retained post carbonization. Although the charcoal itself is dark and opaque, the lighting system utilized permitted the generation of images with strong contrast due to the differences in reflectance among the anatomical elements. Thus usually, in terms of the reflected light intensity, the anatomical elements can be organized from the opaquest to the brightest, in the vessels, axial parenchyma and rays. 
This is very significant because it emphasizes the fact that the texture pattern of the charcoal arises from its anatomical pattern.

The charcoal derived from the native species showed a predominantly diffuse-porous pattern, although semi-ring-porous and ring-porous were also observed (Figure 1). In general, there was a higher occurrence of solitary pores. While twinned pores were observed in Miconia candolleana and Xylopia sericea, multiple pores were observed in Alchornea glandulosa and Cedrela fissilis. The radial pore arrangement was predominant, and clearly evident when noted in the grouped pores. Diagonal and dendritic arrangements were also present in Vismia martiana.

Compared with the Eucalyptus species, seven among the 12 native species exhibited broader and more brilliant rays, C. fissilis and Piptocarpha macropoda, in particular. The other native species revealed opaque and thin rays. The $A$. glandulosa rays were hard to identify. Generally, the axial parenchyma were rather

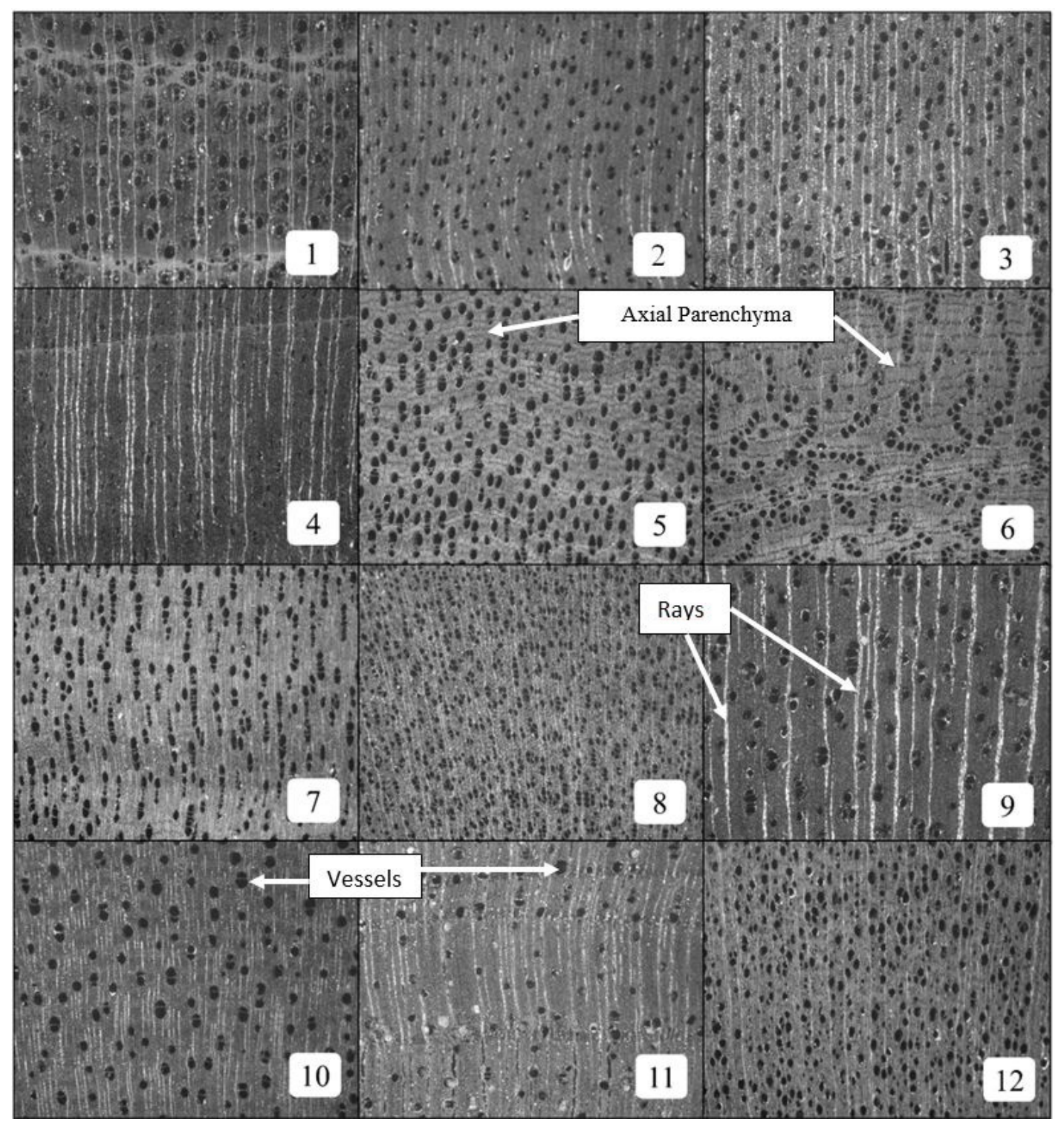

Figure 1. Cross-sectional images of the charcoal samples magnified 25 times: 1) Anadenanthera peregrina; 2) Dyctioloma vandellianum; 3) Trattinnickia ferruginea; 4) Zanthoxylum rhoifolium; 5) Xylopia sericea; 6) Vismia martiana; 7) Alchornea glandulosa; 8) Psidium guajava; 9) Piptocarpha macropoda; 10) Miconia candolleana; 11) Cedrella fissilis; 12) Casuarina equisetifolia. 
indistinct due to the carbonization process, but the confluent and vasicentric types were easier to observe in Anadenanthera peregrina, as the regular bands in C. fissilis and the reticulated ones in V. martiana and $X$. sericea. The charcoals from eucalyptus predominantly revealed a diffuse-porous pattern, diagonal arrangement of the pores, and largely solitary pores, besides opaque and fine rays and poorly defined axial parenchyma (Figure 2).

In Table 2 the selected features are listed. The texture feature selected most often was Homogeneity, after which was Correction. For classification by species,
Homogeneity was also fundamental, with nine features among the 10 selected ones.

Pedrini \& Schwartz (2008) stated that Homogeneity provides high values when small variations occur between the gray levels of the GLCM pixel pairs. Considering only the 10 best texture features chosen for classification by origin (Table 2), Homogeneity, on average, registered higher values for the Eucalyptus samples. In part, this is probably due to the presence of comparatively broader and brighter rays in the native species samples. This implies that because of the high light reflectance, the rays tend to show high

Table 2. Subsets of 10 and 5 features chosen in the selection step.

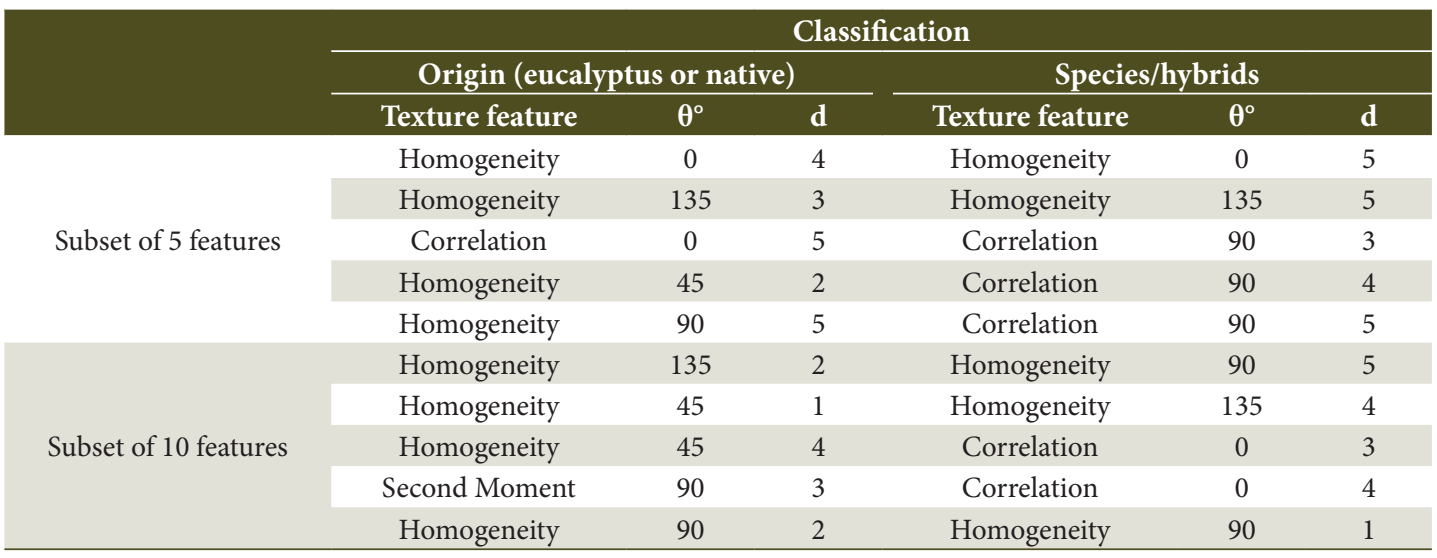

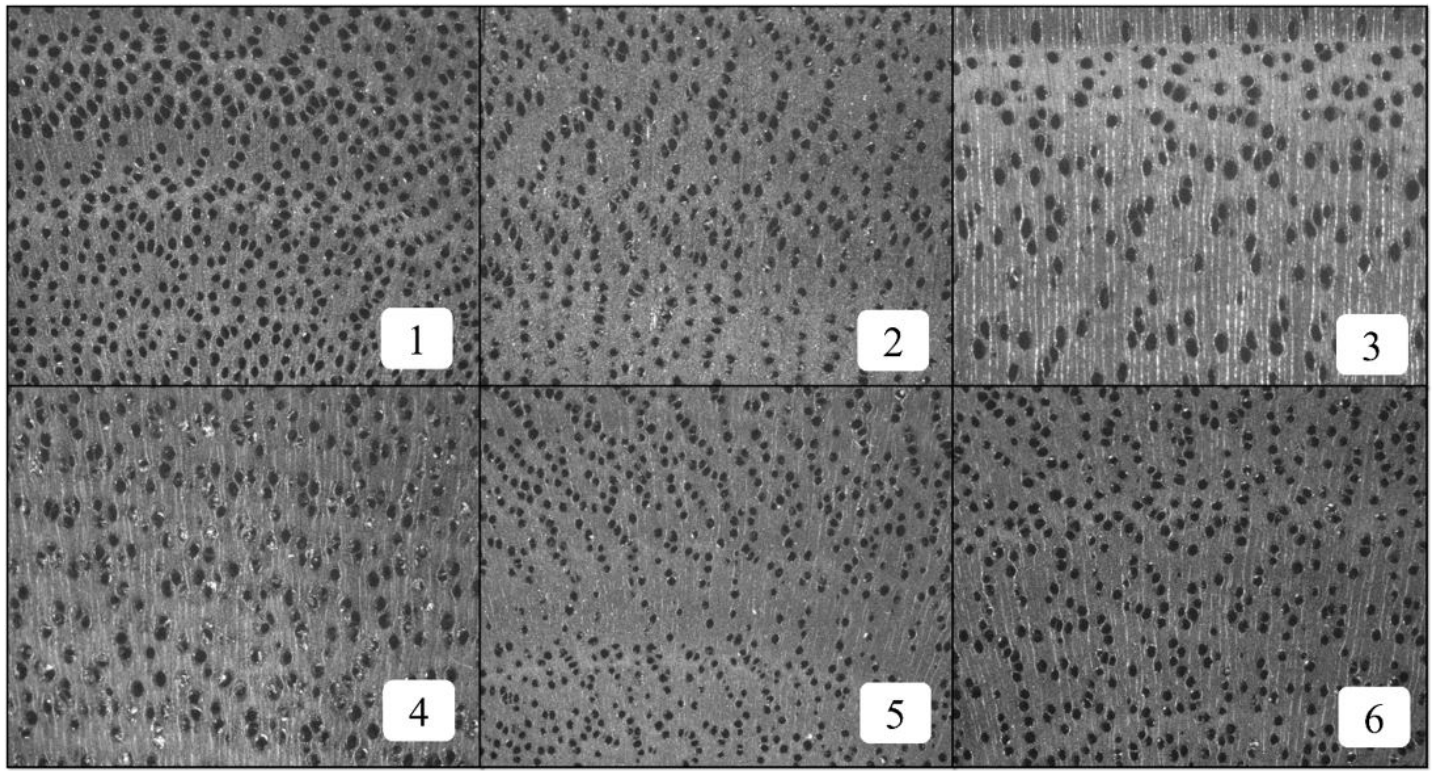

Figure 2. Cross-sectional images of the charcoal samples magnified 25 times: 1) Eucalyptus camaldulensis; 2) Eucalyptus grandis $\times$ Eucalyptus camaldulensis; 3) Eucalyptus urophyla $\times$ Eucalyptus camaldulensis; 4) Eucalyptus. urophyla $\times$ Eucalyptus grandis; 5) Eucalyptus urophylla (clone A); and 6) Eucalyptus urophylla (clone B). 
gray values, which in turn produce a sharp contrast with the vessels, fibers and parenchyma, which mostly have low gray values.

Table 3 lists the findings of the evaluations of all the types of classification tested. For the same number of features, classification by origin revealed a statistically equal performance to the classification by species/hybrids, at 5\% probability level. In all instances employing cross-validation, the use of a greater number of features presented statistically superior performances. It is thus noteworthy that the Kappa index estimates the performance of the classification considering also the random chance of success.. In the classification by origin a probability of one-half of a chance exists, whereas in the classification by species/hybrid, this chance is $1 / 17$. Therefore, for an equal global accuracy, the classification by origin will have a lesser Kappa index than that of the classification by species/hybrid.

The adapted cross-validation resulted in loss of the classification capacity by origin when compared to the use of common cross-validation. Despite this, the results are promising because in this type of validation one can make a direct inference regarding the classification robustness for an unknown species. Thus, the classification by origin utilizing 15 features resulted in $97.9 \%$ accuracy when known species/hybrids samples were tested (meaning these species had samples present in the classifier training stage), and 95\% when testing unknown species/hybrids (meaning these species had no samples present in the classifier training stage).

The adapted cross-validation is unsuitable for species/hybrid classification. Nevertheless, the error matrix produced in such classification reveals intriguing results for the classification by origin. In the classification by species/hybrid, employing 10 features and the adapted cross-validation, $87.2 \%$ of the observations of the native species were classified as some native species, whereas $53 \%$ of the observations of the eucalyptus species were classified as some species of eucalyptus. Thus, this classification exhibited $75.8 \%$ accuracy in terms of origin, which implies that texture analysis is sensitive to the repeated patterns between species and enables one to distinguish between the native species and eucalyptus.

Through the classification based on species/hybrid and utilizing 10 features and cross-validation, $90.4 \%$ accuracy was achieved. In addition, this classification identified the correct origin of the samples with $98 \%$ accuracy. For the successful distinction between the origins, it is irrelevant whether the species is erroneously classified as another species, as long as it is classified as a species belonging to the same origin (Eucalyptus or native). This thus minimizes the error.

Adopting the same reasoning, the classification based on species/hybrid, with 15 features and cross-validation, produced $95 \%$ accuracy. However, this classification identified the correct origin of the samples with $99.4 \%$ accuracy. From the results in Table 2, it is evident that the classification by species/hybrids tends to have higher accuracy than the classification by origin when the goal is solely the distinction between the native and eucalyptus species. This is likely because in the classification by species/hybrid each class is inclined to exhibit less variability as it is represented by only a single species/hybrid, which would promote the segregation of the patterns of each class within the feature space.

Table 3. Evaluation parameters of the classifications tested.

\begin{tabular}{|c|c|c|c|c|c|c|c|c|c|}
\hline Classification & No. of features & Validation & Accuracy (\%) & Kappa & & & & & \\
\hline \multirow{6}{*}{ By origin } & 15 & \multirow{3}{*}{ Cross-validation } & 97.9 & 0.953 & $\mathrm{a}$ & & & & \\
\hline & 10 & & 96.2 & 0.916 & & $\mathrm{~b}$ & c & & \\
\hline & 5 & & 83.9 & 0.725 & & & & & $\mathrm{f}$ \\
\hline & 15 & \multirow{3}{*}{ Adapted Cross-validation } & 95.0 & 0.889 & & & c & $\mathrm{d}$ & e \\
\hline & 10 & & 93.0 & 0.845 & & & & & $\mathrm{e}$ \\
\hline & 5 & & 73.0 & 0.426 & & & & 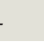 & \\
\hline \multirow{3}{*}{ By species } & 15 & \multirow{3}{*}{ Cross-validation } & 95.0 & 0.947 & $\mathrm{a}$ & $\mathrm{b}$ & & & \\
\hline & 10 & & 90.4 & 0.898 & & & c & $\mathrm{d}$ & \\
\hline & 5 & & 71.6 & 0.697 & & & & & f \\
\hline
\end{tabular}

All the Kappa indexes statistically differed from zero by the Z-test at $5 \%$ probability level. Kappa indexes followed by the same letter in the column do not differ statistically from each other by Test $Z$ at $5 \%$ probability level. 
Table 4 lists the percentage of errors for each species and hybrid with respect to the two classification types studied. $D$. vandellianum exhibited the highest percentage of error in the classification by origin. As evident from Figures 1 and 2, this native species is probably visually the closest to the genus Eucalyptus with respect to the anatomical patterns and texture. This similarity occurs principally due to the presence of opaque rays, mostly isolated pores and poorly defined axial parenchyma. Besides, these characteristics produce regions with less contrast between the gray levels of the adjacent pixels, which may be the cause for the high homogeneity values, as is apparent in the images of the eucalyptus species.

The $D$. vandellianum species also displayed the highest percentage error when evaluation was done

Table 4. Classification error of each species/hybrid in the classifications by origin and by species using 10 features and cross-validation.

\begin{tabular}{|lcc|} 
& \multicolumn{2}{c}{ Classification error (\%) } \\
\cline { 2 - 3 } Species/hybrid & Origin & $\begin{array}{c}\text { Species/ } \\
\text { hybrid }\end{array}$ \\
\hline Anadenanthera peregrina & 6 & 20 \\
\hline Dyctioloma vandellianum & 34 & 40 \\
\hline Eucalyptus camaldulensis & 4 & 18 \\
\hline Trattinnickia ferruginea & 0 & 2 \\
\hline E. grandis $\times$ E. camaldulensis & 0 & 4 \\
\hline Zanthoxylum rhoifolium & 2 & 22 \\
\hline Xylopia sericea & 0 & 6 \\
\hline Vismia martiana & 0 & 6 \\
\hline E. urophylla $\times$ E. camaldulensis & 8 & 2 \\
\hline E. urophylla $\times$ E. grandis & 8 & 10 \\
\hline Eucalyptus urophylla & 2 & 8 \\
\hline Alchornea glandulosa & 0 & 0 \\
\hline Psidium guajava & 0 & 0 \\
\hline Piptocarpha macropoda & 0 & 14 \\
\hline Miconia candolleana & 2 & 18 \\
\hline Cedrella fissilis & 2 & 2 \\
\hline Casuarina equisetifolia & 0 & 0 \\
\hline
\end{tabular}

for the classification by species/hybrid, followed by $Z$. rhoifolium and A. peregrina. In general, the native species were observed to show a higher percentage of error than the eucalyptus species. For a more comprehensive investigation into the causes that lead to the misclassification of species, further research is required with the aim of analyzing the relationship between the texture features drawn with GLCM and the intrinsic anatomical characteristics of each species.

Care should be taken when comparing these results with those recorded in the literature. Several factors must be considered, like the number of features employed in the classification, the presence and type of selection of the features, types of features, types of classifiers and number of classes. Utilizing the Kappa index is significant because it enables the comparison between the classifiers with different numbers of classes. However, in the literature relating to this subject, only the Global Accuracy of classification is used. As this work is a pioneering effort focused on the application of image analysis for the recognition of the carbonized species, comparisons have been performed with the existing studies that have utilized texture analysis to differentiate between the woody species, as shown in Table 5.

This study achieved $90.4 \%$ accuracy for the classification by species/hybrid utilizing only 10 features. Therefore it was numerically inferior to the findings reported in other research works available in the literature. Nevertheless, it is significant that, despite having the lowest accuracy, this classification also reveals the lowest ratio between the number of features and number of classes. When 15 features were included, the accuracy rose to $95 \%$, exactly identical to the accuracy reported by Khalid et al. (2008). Further, such classification was numerically inferior only to the researches that employed a higher ratio between

Table 5. Summary of work with regard to identification of the woody species from the analysis of images.

\begin{tabular}{|lcccc|}
\multicolumn{1}{c}{ Authors } & No. of features & No. of classes & Accuracy (\%) & No. of features \\
\hline Khalid et al. (2008) & 20 & 20 & No. of classes \\
\hline Yusof et al. (2013) & 51 & 23 & 95.0 & 100 \\
\hline Paula et al. (2014) & 2284 & 41 & 98.7 & 222 \\
\hline Zamri et al. (2016) & 38 & 52 & 97.8 & 5570 \\
\hline This work & 10 & 17 & 91.7 & 73 \\
\hline This work & 15 & 17 & 90.4 & 89 \\
\hline
\end{tabular}


the number of features and number of classes, as shown by Yusof et al. (2013) and Paula et al. (2014).

The carbonization process disregards or distorts some of the visual and anatomical data originally present in the wood, posing a greater degree of difficulty in recognizing the species when compared with the identification based on the in natura wood. Therefore, when compared with the works done on species identification from wood (Table 5) it is evident that the potential of texture analysis is quite good.

\section{CONCLUSIONS}

All the classifications tested were observed to be statistically superior to a randomized classification (Kappa $>0$ ), giving 97.9\% accuracy for the classification by origin and $95 \%$ accuracy for the classification by species, utilizing 15 characteristics of texture.

Texture analysis was proven to be an effective tool, showing good potential both for the classification of charcoal by origin, as well as for the classification by species. The classification by origin was efficacious even for the evaluation of species not included during the classifier training stage. Hence texture analysis is a robust method.

Although the technique offers promise, further investigations continue to be required to estimate the effect of the various sources of anatomical variability within the same tree, particularly the variations present in the medulla-bark direction. For convenience, research in the future must focus on simpler means of image acquisition to facilitate the classification in loco.

\section{ACKNOWLEDGEMENT}

The authors would like to thank the Laboratório de Painéis e Energia da Madeira (LAPEM/UFV), the Laboratório de Propriedades da Madeira (LPM/UFV), the Fundação de Amparo à Pesquisa de Minas Gerais (FAPEMIG), the Coordenação de Aperfeiçoamento de Pessoal de Nível Superior (CNPq) and the Coordenação de Aperfeiçoamento de Pessoal de Nível Superior CAPES, for their support.

\section{SUBMISSION STATUS}

Received: 29 dec., 2017

Accepted: 10 jun., 2018

\section{CORRESPONDENCE TO}

\section{Bruno Geike de Andrade}

Instituto de Florestas, Universidade Federal Rural do Rio de Janeiro - UFRRJ, Rodovia BR 465, Km 7, CEP 23897-000, Seropédica, RJ, Brasil e-mail: br_geike@yahoo.com.br

\section{FINANCIAL SUPPORT}

This study was financed in part by the Coordenação de Aperfeiçoamento de Pessoal de Nível Superior - Brasil (CAPES) - Finance Code 001.

\section{REFERENCES}

Associação Mineira de Silvicultura - AMS. Anuário estatístico 2012. Belo Horizonte: AMS; 2013.

Congalton RG. A review of assessing the accuracy of classifications of remotely sensed data. Remote Sensing of Environment 1991; 37(1): 35-46. http://dx.doi. org/10.1016/0034-4257(91)90048-B.

Fisher RA. The use of multiple measurements in taxonomic problems. Annals of Eugenics 1936; 7(2): 179-188. http:// dx.doi.org/10.1111/j.1469-1809.1936.tb02137.x.

Food and Agriculture Organization of the United Nations - FAO. FAOSTAT - Forestry [online]. Rome: FAO; 2017 [cited 2017 Dec 29]. Available from: http://www.fao.org/ faostat/en/\#data/FO

Gonçalves TAP, Ballarin AW, Nisgoski S, Muñiz GIB. Contribution to the identification of charcoal origin in Brazil I - anatomical characterization of corymbia and eucalyptus. Maderas. Ciencia y Tecnología 2014; 16(3): 323-336.

Gonçalves TAP, Marcati CR, Scheel-Ybert R. The effect of carbonization on wood structure of Dalbergia Violacea, Stryphnodendron Polyphyllum, Tapirira Guianensis, Vochysia Tucanorum, and Pouteria Torta from the Brazilian Cerrado. International Association of Wood Anatomists Journal 2012; 33(1): 73-90. http://dx.doi. org/10.1163/22941932-90000081.

Gonçalves TAP, Nisgoski S, Oliveira JS, Marcati CR, Ballarin AW, Muñiz GIB. A contribution to the identification of charcoal origin in Brazil II - Macroscopic characterization of Cerrado species. Anais da Academia Brasileira de Ciências 2016; 88(2): 1045-1054. http://dx.doi.org/10.1590/00013765201620150322 . PMid:27192198.

Gonçalves TAP, Scheel-Ybert R. Charcoal anatomy of Brazilian species. I. Anacardiaceae. Anais da Academia Brasileira de Ciências 2016;88(3 Suppl): 1711-1725. http://dx.doi.org/10.1590/0001-3765201620150433. PMid:27901191. 
Haralick RM, Shanmugam K, Dinstein I. Textural features for image classification. IEEE Transactions on Systems, Man, and Cybernetics 1973; 6(6): 610-621. http://dx.doi. org/10.1109/TSMC.1973.4309314.

Hudson WD, Ramm CW. Correct formulation of the kappa coefficient of agreement. Photogrammetric Engineering and Remote Sensing 1987; 53(4): 421-422.

IAWA Committee. List of microscopic features for hardwood identification. International Association of Wood Anatomists Bulletin 1989; 10(2): 219-332.

Ibrahim I, Khairuddin ASM, Talip MSA, Arof H, Yusof $\mathrm{R}$. Tree species recognition system based on macroscopic image analysis. Wood Science and Technology 2017; 51(2): 431-444. http://dx.doi.org/10.1007/s00226-016-0859-4.

Industria Brasileira de Árvores - IBÁ. Relatório Ibá [online]. São Paulo: IBÁ; 2017 [cited 2017 Dec 29]. Available from: http://iba.org/images/shared/Biblioteca/ IBA_RelatorioAnual2017.pdf

Khalid M, Yusof R, Liew E, Nadaraj M. Design of an inteligent Wood species recognitions system. International Journal of Simulation System - Science and Technology 2008; 9(3): 9-19.

Martins JG, Oliveira LS, Britto AS Jr, Sabourin R. Forest species recognition based on dynamic classifier selection and dissimilarity feature vector representation. Machine Vision and Applications 2015; 26(2-3): 279-293. http:// dx.doi.org/10.1007/s00138-015-0659-0.

MathWorks. Statistics and machine learning Toolbox ${ }^{\mathrm{Ts}}$ user's guide. Natick: The MathWorks; 2017. 9440 p.

Muñiz GIB, Carneiro ME, Batista FRB, Schardosin FZ, Nisgoski S. Wood and charcoal identification of five species from the miscellaneous group known in brazil as "angelim" by near-ir and wood anatomy. Maderas. Ciencia y Tecnología 2016; 18(3): 505-522.

Muñiz GIB, Carneiro ME, Nisgoski S, Ramirez MGL, Magalhães WLE. SEM and NIR characterization of four forest species charcoal. Wood Science and Technology 2013; 1(4): 10-22. http://dx.doi.org/10.1007/s00226-013-0539-6.

Muñiz GIB, Nisgoski S, França RF, Schardosin FZ. Anatomia comparativa da madeira e carvão de Cedrelinga catenaeformis Ducke e Enterolobium schomburgkii Benth. para fins de identificação. Scientia Forestalis 2012b; 40(94): 291-297.

Muñiz GIB, Nisgoski S, Schardosin FZ, França RF. Anatomia do carvão de espécies florestais. Cerne 2012a; 18(3): 471477. http://dx.doi.org/10.1590/S0104-77602012000300015.

Nisgoski S, Muñiz GIB, França RF, Batista FRR. Anatomia do lenho carbonizado de Copaifera cf. langsdorfii Desf. e Dipteryx odorata (Aubl.) Wild. Ciência da Madeira 2012; 3(2): 66-79. http://dx.doi.org/10.12953/2177-6830. $\mathrm{v} 03 \mathrm{n} 02 \mathrm{a} 01$.
Nisgoski S, Muñiz GIB, Gonçalves TAP, Ballarin AW. Use of visible and near-infrared spectroscopy for discrimination of eucalypt species by examination of solid samples. Journal of Tropical Forest Science 2017a; 29(3): 371-379. http:// dx.doi.org/10.26525/jtfs2017.29.3.371379.

Nisgoski S, Muñiz GIB, Morrone SR, Schardosin FZ, França RF. NIR and anatomy of wood and charcoal from Moraceae and Euphorbiaceae species. Ciência da Madeira 2015; 6(3): 183-190. http://dx.doi.org/10.12953/2177-6830/ rcm.v6n3p183-190.

Nisgoski S, Oliveira AA, Muñiz GIB. Artificial neural network and SIMCA classification in some wood discrimination based on near-infrared spectra. Wood Science and Technology 2017b; 51(4): 929-942. http:// dx.doi.org/10.1007/s00226-017-0915-8.

Oliveira AA, Siqueira PH, Nisgoski S, Muñiz GIB, Ferreira JH. Identificação de Madeiras utilizando a Espectrometria no Infravermelho Próximo e Redes Neurais Artificiais. Tendências em Matemática Aplicada e Computacional 2015; 16(2): 81-95. http://dx.doi.org/10.5540/tema.2015.016.02.0081.

Paula PL Fo, Oliveira LS, Nisgoski S, Britto AS Jr. Forest species recognition using macroscopic images. Machine Vision and Applications 2014; 25(4): 1019-1031. http:// dx.doi.org/10.1007/s00138-014-0592-7.

Pedrini H, Schwartz WR. Análise de imagens digitais: princípios, algoritmos e aplicações. São Paulo: Thomson Learning; 2008. 508 p.

Piuri V, Scotti F. Design of an automatic wood types classification system by using fluorescence spectra. IEEE Transactions on Systems, Man and Cybernetics. Part C, Applications and Reviews 2010; 40(3): 358-366. http:// dx.doi.org/10.1109/TSMCC.2009.2039479.

Ramalho FMG, Hein PRG, Andrade JM, Napoli A. Potential of near-infrared spectroscopy for distinguishing charcoal produced from planted and native wood for energy purpose. Energy \& Fuels 2017; 31(2): 1593-1599. http:// dx.doi.org/10.1021/acs.energyfuels.6b02446.

Scheel-Ybert R, Gonçalves TAP. Primeiro atlas antracológico de espécies brasileiras. Rio de Janeiro: Museu Nacional; Universidade Federal do Rio de Janeiro; 2017.

Wang HJ, Zhang G, Qi H. Wood recognition using image texture features. PLoS One 2013; 8(10): e76101. http:// dx.doi.org/10.1371/journal.pone.0076101. PMid:24146821.

Yusof R, Khalid M, Khairuddin ASM. Application of kernel-genetic algorithm as nonlinear feature selection in tropical wood species recognition system. Computers and Electronics in Agriculture 2013; 93: 68-77. http:// dx.doi.org/10.1016/j.compag.2013.01.007.

Zamri MIPB, Khairuddin ASM, Mokhtar N, Yusof R. Statistical feature extraction method for wood species recognition system. world academy of Science, Engineering and Technology International Journal of Computer and Information Engineering 2016; 10(3): 441-444. 